\title{
Employee Satisfaction as per Working Environment in King Salaman Military Hospital, Tabuk, Saudi Arabia
}

\author{
Khalid Alazab ${ }^{1}$ \\ ${ }^{1}$ Tabuk, Saudi Arabia \\ Correspondence: Khalid Alazab, Tabuk, Saudi Arabia. E-mail: khalid_alazab@hotmail.com
}

Received: May 28, 2018

Accepted: October 2, $2018 \quad$ Online Published: October 11, 2018

doi:10.5539/ibr.v11n11p67

URL: https://doi.org/10.5539/ibr.v11n11p67

\begin{abstract}
In the current knowledge economy, it is important for organizations to utilise their resources in growing a favourable working environment for its employees. Development and sustenance of a reliable working environment is a prerequisite for a company to achieve effective growth and maximum productivity in the current era of cut throat competition. Job satisfaction is directly linked with a healthy work environment and researches have indicated the presence of several components in determining the job satisfaction rate for any employee. This research has used a cross-sectional descriptive design within the premises of King Salaman Military hospital in Tabuk. The data was collected through questionnaire from 139 employees of King Salaman Military hospital. The research has found that the overall satisfaction has a statistical relationship with gender and nationality whereas no statistical relationship was observed between nature of work and overall satisfaction, educational level, age group, and years of experience.
\end{abstract}

Keywords: employee, hospital, job satisfaction, Saudi Arabia, work environment

\section{Introduction}

The current economic scenario prevalent in the corporate sector around the globe compels the industries to cater the needs of their employees to sustain their market position and revenues (Glebe, 2009). The environment and external factors aren't usually in the control of company's employees and management but the internal conditions can be influenced and gauged to harbour competent working employees for long term growth of the company. The human resource department is regarded as the key influencer for maintaining a compatible working environment within a company. The relationship between employee satisfaction and the working environment of the company is a leading theoretical subject, pursued by many authors and scholars alike (Wright, 2001).

The significance of work environment in job satisfaction cannot be ruled out in any of the circumstances. In the past, studies have been conducted to relate and establish the link between employee satisfaction and productivity/performance (Smits, 1972). The results overwhelmingly however, pointed out the association between employee satisfaction and the working environment. Same set of principles can be applied to the general health industry which plays a crucial role in determining the direction of society. Employee satisfaction and job retention are vital to smooth growth and running of hospitals and healthcare centres around the globe.

In the current knowledge economy, employee satisfaction has become a matter of great concern for all organizations. Over the years, organizations have realized that employee's performance and productivity centres on the spectrum of job satisfaction. The working environment within a firm can be categorised as the most vital element towards attainment of job satisfaction for any individual. Cherogony \& Wapangana (2017) have pointed that the efficiency of employees is directly related to the working environment of the organization. Moreover, a decline in job satisfaction rate is always exponentially related to deteriorating working conditions. It has been observed that often the employees leave a company because of its unhealthy environment and mismanagement at the middle or upper level (Carsten, 2006). The prevalent conditions of job satisfaction and working environment aren't taken seriously by the employers in majority of organizations that is a matter of concern. Identification, prevention and rectification of these problems can be managed through an effective human resource management strategy.

Over the years, healthcare industry has turned into a complex paradigm of patient well-being and technology coupled with increasing demands and daily stress. The fundamental transformations in the industry has propelled 
the employees to consider the factors of working environment, job retention and satisfaction (Jooste, 2003). It has been observed that job satisfaction in healthcare industry is related to multiple factors such as timing, role of administration, communication, and working environment (Freeborn \& Hooker, 1995).

Zaghloul et al. (2008) observed that the problems faced by Saudi Arabia in health sector are primarily based on the shortage of staff and absence of a healthy working environment. Miller-Rosser et al. (2009) have pointed that healthcare system in Saudi Arabia is gradually improving and adapting according to world standards but the level of Job satisfaction and working environment needs a focused attention of the relevant authorities.

The current paper seeks to evaluate and analyse employee satisfaction as per working environment in King Salaman Military Hospital, Tabuk, Saudi Arabia. Specifically, the research objectives laid out by the paper shall focus on the factors of employee satisfaction and the working environment of the hospital.

\subsection{Research Questions and Objectives}

The objective of this paper is to investigate the level of employee satisfaction as well as to examine the overall environment and to assess the level of satisfaction based on the factors like gender, age, income, occupation and experience in the King Salaman Military Hospital, Tabuk, Saudi Arabia.

In the light of observed research objective, following main research questions have been indicated in this paper.

- Generally, are the employees satisfied with the overall working environment of the hospital?

- Is there any disparity in the level of job satisfaction when compared on the basis of gender, age, income, experience and occupation?

\subsection{Research Hypothesis}

Research provide evidence how an ideal, and supportive working environment enables the workers to utilise the best of their knowledge, abilities and skills to effectively solve the problems at hand (Leshabari, 2008). A simple causal relationship was needed to define the parameters of job satisfaction and working environment in the hospital. In the present case, the overall satisfaction rate of employees within the hospital is the dependent variable and gender, nationality, nature of work and experience level are independent variables. The literature studied for this purpose had defined attributes of certain independent variables which might cast an impact on the job satisfaction rate of the involved participants but as we are just observing the overall picture and not the details of the working environment, it should be clear that selection of null and alternate hypothesis has been defined to accommodate the simplistic nature of this study. Our paper takes into account certain positive indicators on the basis of which, job satisfaction rate is determined. The availability of such straightforward and simple hypothesis has added to the discreet nature of this study with upfront objective of determination of job satisfaction ratio in the hospital staff.

Therefore in order to check if there is a relationship between job satisfaction and working environment the following hypothesis were formulated:

H1: The overall satisfaction of employees have significant relationship with working environment of the hospital.

$\mathrm{H} 2$ : The overall satisfaction of employees have no significant relationship with working environment of the hospital.

\section{Literature Review}

A supportive work environment has always been considered as vital to job satisfaction of employees. It has to be noted that work environment is the constituent of many factors that significantly influence the physical and psychological health of an individual. The working environment is often calibrated in terms of trust, wages, and relationship with management. It comes as a challenge for today's organizations to create a comfortable environment within the company to harnesses high level of job satisfaction.

The fundamental change in the health sector of Saudi Arabia can be observed in terms of unavailability of local staff or dominant involvement of foreign doctors and nurses (Al-Ahmadi, 2009). A job satisfaction study, conducted by Bhuian et al. (1996) used exploratory methodology to ascertain the relationship between job characteristics and quality of work life. The results of other studies revealed that working environment and growth opportunities were the critical factors in job satisfaction (Mitchell, 2009; Zaghloul et al., 2008). A study by Al-Dossary et al. (2012) revealed that satisfaction level of employees were closely affiliated with factors such as income, timing and leadership style while dissatisfaction was mostly dependent on the lack of recognition, working policies, hospital environment and relationships with peers. A similar study by Zaghloul et al. (2008) revealed that lack of motivation and absence of a good salary package are the leading causes of dissatisfaction in Saudi Arabia. 
Kreitner (2004) described job satisfaction as an emotional response to various aspects of employee needs within the office. Though the working dynamics have evolved exponentially in the previous decades, the theoretical concept of job satisfaction is still associated with the work of Hoppock (1935), who defined it as any circumstances within the place of work that causes a level of contentment and joy for the employee. Considering the overall picture, most of the definitions and roles of job satisfaction rely on the emotional well-being of an employee. It could cover the overall nature of job or some specific components of it (Lu et al., 2005). Moreover, the results subscribed with the job objectives also dictate the level of job satisfaction for an employee, so in theory the overall situational analysis for the job description can be linked to the assessment of job satisfaction based on working environment (Judge et al., 2002).

Studying work environment in the healthcare sector, Lewy (1991) stated that hospital workforce face one of the most stressful and challenging working environments where they constantly have to meet the demands and requirements of patients. People working in healthcare sector have the ability to influence and affect the experience and quality of services being provided to patients (Schoombie et al., 2014). Moreover, the healthcare professionals are at the highest risk of stress and work pressure thus establishing the fact that work environment and working conditions are integral to wellbeing of the workers. Organizations having a friendly work environment tend to have more productivity and financial stability (Kreitzer et al., 1997). Swansburg (1996) is of the view that within the context of healthcare sector, the work environment set forth by the management of hospitals determine the behaviour of working staff which in turn determines the environment perceived by patients. Moorhead and Griffin (1998) pointed that management of any organization including the healthcare sector can set the tone for the overall working environment and subsequently the job satisfaction of employees.

Human resource management and strategy is an important component of company's overall plan to harness job satisfaction. Human resources can be referred to as the sum total of people working for an employer while utilising their skills, abilities and knowledge (Drasnfield, 2001). It is evident that the organizations that prioritizes the experience of their employees along with a healthy working environment by utilizing their resources to actively engage and look after the employees are in a better position of increasing their efficiency and maximizing their productivity. Management of individuals is related with utilization and handling of staff appropriately at various locations and projects to suit the company's objectives and goals. It is the responsibility of human resource department to effectively maintain a healthy and growing working environment with the presence of positive indicators. The coming sections will illustrate the evaluation of working environment at King Salaman Military Hospital, Tabuk, Saudi Arabia. This will assist in defining parameters for the current study as well as laying foundation for further research.

\section{Methodology}

\subsection{Research Design}

This research adopted quantitative method according to the nature of the study and its objectives. Under quantitative method, the current study of employee satisfaction as per working environment in King Salaman Military Hospital, Tabuk, Saudi Arabia, a cross-sectional descriptive research design was employed.

Descriptive research is a study design that is accurate to depict the participants in an accurate manner. It is being utilised when some specific components or variables are related to people in the experimental population (Zikmund, 2003). It actually contains a certain set of defined questions with fixed elements (Malhotra et al., 2006). In the same context, a research study that employs a single data collection technique is referred to as a cross sectional (Easterby-Smith et al., 1991). This method is employed when quick results are required for the analysis of causal associations.

\subsection{Data Collection Method}

The current study used the questionnaire for data collection purpose that is a technique of survey strategy. The online questionnaire method was employed for the purpose of testing hypothesis. The choice of questions took care of the factors like confidentiality of information, secrecy, anonymity, clarity, and convenience for respondents. After development and formulation of a suitable questionnaire with relevant demographic and technicalities, it was sent to the 200 randomly selected employees of King Salman Military Hospital Tabuk out of which 139 responded that marks a response rate at $70 \%$.

\subsection{Data Analysis}

The data analysis was carried out by using SPSS 24. First of all, descriptive analysis was done to get mean, percentages, frequencies, and standard deviation for all demographic data followed by independent $\mathrm{T}$ test to test the hypothesis. As with most studies, there were several impeding factors like shortage of time and low response 
rate of employees (Only 139 out of 200 employees filled out the questionnaire) to the proposed study which might have affected the overall result calibration of the tests.

\section{Results}

The results have been compiled and evaluated based on the findings and analysis of the SPSS. The results reflect the overall findings of our paper with focus on job satisfaction and working environment. It has to be noted that these results are purely based on the available data and no alterations have been made to reconfigure the outlined information.

Table 1. Relationship between overall satisfaction and gender

\begin{tabular}{|c|c|c|c|c|}
\hline \multicolumn{5}{|c|}{ Overall Satisfaction } \\
\hline Gender & $\mathbf{N}$ & Mean & SD & P Value \\
\hline Male & 102 & 3.493 & .5633 & .008 \\
\hline Female & 37 & 3.212 & 4883 & \\
\hline
\end{tabular}

Note. $\mathrm{SD}=$ standard deviation

Table 1 shows the statistical relationship between Overall satisfaction and gender, as the p-value is less than 0.05 Male members are more satisfied than females as the satisfaction score of males is significantly higher than females.

Table 2. Relationship between Overall satisfaction and nationality

\section{Overall Satisfaction}

\begin{tabular}{clccc} 
Nationality & N & Mean & SD & P Value \\
\hline Saudi & 124 & 3.393 & .568 & .029 \\
Non Saudi & 12 & 3.760 & .284 & \\
\hline
\end{tabular}

Note. $\mathrm{SD}=$ standard deviation

Table 2 indicates that there is a statistical relationship between overall satisfaction and nationality of employee, as again the p-value is less than 0.05 . Non-Saudi members are significantly more satisfied than Saudi nationals.

Table 3. Relationship Between Nature of Work and Overall Satisfaction

\begin{tabular}{lcccc}
\hline $\begin{array}{l}\text { Overall Satisfaction } \\
\text { Nature of Work }\end{array}$ & N & Mean & SD & P Value \\
\hline Administrative & 95 & 3.407 & .570 & .592 \\
Technical & 42 & 3.463 & .531 & \\
\hline
\end{tabular}

Note. $\mathrm{SD}=$ standard deviation

Table 3 shows there is no statistical relationship between nature of work and overall satisfaction because the p-value is very high.

Table 4. Relationship between Overall satisfaction, educational level, age group, and years of experience

\begin{tabular}{llllllc}
\hline \multicolumn{2}{c}{ Overall Satisfaction } & SS & df & MS & F Value & Sig. \\
\hline Age Group & Within groups & 1.00 & 2 & .500 & 1.18 & .56 \\
& Between groups & 80.68 & 136 & .593 & & \\
Total & 81.68 & 138 & & & \\
Educational & Between groups & 122.03 & 136 & .89 & 3.58 & .24 \\
Level & Within groups & .50 & 2 & .25 & & \\
& Total & 122.53 & 138 & & & \\
Years of & Between groups & 182.32 & 136 & 1.34 & 5.36 & .17 \\
Experience & Within groups & .50 & 2 & .25 & & \\
& Total & 182.82 & 138 & & & \\
\hline
\end{tabular}

Note. $\mathrm{SS}=$ sum of squares; $\mathrm{MS}=$ mean square;

While comparing the Educational level, Age group, and Years of experience with overall satisfaction, there is no statistical relationship observed between these as the $\mathrm{P}$ Value in all variables is greater than 0.05 . This result presents an interesting association of the assumed connection between different factors and the actual summary 
of outcomes. The elements discussed within the statistical analysis contribute towards revelation of segmented information.

Table 5. Distribution of participants as per their overall evaluation of working environment

\begin{tabular}{llcc}
\hline Indicator & Mean & SD & Rank \\
\hline Participation and effects & 3.89 & 62 & 1 \\
salary and other financial motivation & 2.82 & .94 & 9 \\
working environment & 2.99 & 1.03 & 8 \\
security and comfort ability & 3.48 & .674 & 5 \\
Leadership & 3.05 & .79 & 7 \\
respecting efforts & 3.68 & .88 & 4 \\
Working satisfaction & 3.82 & .75 & 2 \\
Training and performance development & 3.73 & .73 & 3 \\
Social Environment & 3.30 & .70 & 6 \\
Overall Evaluation of all Indicators & 3.4 & .55 & 5 \\
\hline
\end{tabular}

Note. $\mathrm{SD}=$ standard deviation

In order to verify the relationship between overall satisfaction and working environment, 9 indicators were used and results are summarized in table 5. The overall satisfaction of participants to all indicators is 3.4 out of 5, which exhibits the notion of 'satisfied' but the analysis of the ranking of these indicators according to their satisfaction degree, it is evident that some have strong and some have weak relationship with working environment.

\section{Discussion}

This study has used quantitative research method with a questionnaire on a sample of employees of King Salman Military Hospital Tabuk, Saudi Arabia. The aim of this study was to investigate the level of employee satisfaction as per the working environment of the hospital.

H1 upheld that overall satisfaction of employees have significant relationship with working environment of the hospital. The research findings shows that the overall satisfaction of participants to nine indicators have significant relationship with working environment of the hospital that lead us to accept H1. However, all these indicators have different satisfaction degrees. Working satisfaction, training and performance development have the highest rank and salary and other financial motivation represent lower rank. The comparison of gender and nationality with overall satisfaction shows a significant statistical relationship but results for age group, educational level, nature of work and years of experience show no statistical relationship with overall satisfaction.

According to the literature review, the subject of job satisfaction and its relation with working environment has been in active discussion but there are not so many empirical studies that investigate the relationship between employee satisfaction and environment in hospital settings. In order to establish this relationship, it was needed to select suitable indicators of employee satisfaction. In the same context, a parallel study by Dawson et al. (2017) prioritised the investigation of job satisfaction and its link with nature of employment, i.e. full time and part time. It was revealed that job satisfaction had no particular influence from the nature of job and that it was an independent variable with no consequences on career contentment. The same was effectively demonstrated by our sub-indicators in the above results. Another research by Sumner \& Niederman (2004) sought to reflect the findings in an analysis of gender role in job satisfaction. It was widely speculated that job satisfaction rate might be closely linked with gender roles and the approach taken to cater job description. The result however casted a different scenario where no or very minute connection was established between gender roles and the job satisfaction rate, terming the overall debate void. The same was exhibited by our study of positive indicators and independent variables correlation. Gil \& Mataveli (2017) rightly points out in his study that job satisfaction can only be linked with social and physical parameters of working environment and circumstances. The assumed connection of job satisfaction with virtual parameters of age, gender or nature of work are only speculative and hold no real association (Zeffane \& Bani Melhem, 2017).

\section{Conclusion}

This objective of this study was to explore the relationship between employee satisfaction and working environment in King Salman Military Hospital Tabuk, Saudi Arabia. The paper draws a relationship between several factors and indicators in the hospital setting to study the effect of working environment on job satisfaction. It was observed and analysed in the result section that several elements were responsible for job satisfaction of employees in King Salman Military Hospital. The productivity, effectiveness and performance of an employee is directly dependent on his working environment and subsequently affect the job satisfaction rate. 
It can be concluded that the study conducted in the Military hospital, Saudi Arabia was fundamental in determining the overall picture of job satisfaction, The age, experience, gender and nationality was in no way connected to job satisfaction, rather it was connected to the overall work environment of the hospital. Finally, it has to be noted that, work environment within the hospital is an effective estimate of the overall long term sustainability and performance of the hospital employees.

The basic strength of this study lies in its simple cross sectional approach to analyse and cater the problem of job satisfaction scrutiny at the subjected hospital. The development and implementation of this study in the hospital has given rise to certain indicative parameters that can be utilised effectively to counter the problems causing the dissatisfaction among employees.

One of the major limitations of this study is its restricted generalizability. Since the study only covers the staff of particular hospital, the small population of that hospital along with demographic indicators do not allow the results of the study to be generalized to other organizations. Thus, the impact and correlation of this study with the corporate world might be questionable.

This study has practical implications for the development of organizational productivity and performance improvement through a systematic inference of available data. Job satisfaction has always been closely affiliated with the adjoining parameters of productivity, performance and work efficiency (Schleicher, 2004). Thus, the results of this paper can be actively employed to harness and develop these characteristics which aim at fulfilment of career and professional objectives for most of the employees.

\section{References}

Aldossary, A., While, A., \& Barriball, L. (2008). Health care and nursing in Saudi Arabia. International nursing review, 55(1), 125-128. https://doi.org/10.1111/j.1466-7657.2007.00596.x

Al - Dossary, R., Vail, J., \& Macfarlane, F. (2012). Job satisfaction of nurses in a Saudi Arabian university teaching hospital: a cross - sectional study. International nursing review, 59(3), 424-430. https://doi.org/10.1111/j.1466-7657.2012.00978.x

Bhuian, S. N., Al-Shammari, E. S., \& Jefri, O. A. (1996). Organizational commitment, job satisfaction and job characteristics: An empirical study of expatriates in Saudi Arabia. International Journal of Commerce and Management, 6(3/4), 57-80. https://doi.org/10.1108/eb047336

Carsten, J. (2006). The 7 hidden reasons employees leave: How to recognize the subtle signs and act before it's too late. Personnel Psychology, 59(1), 246.

Cherogony, E., \& Wapangana, M. M. (2017). An Assessment of the Role of Working Environment on Performance of Nurses in Devolved Health Services in Baringo County, Kenya. International Journal of Innovative Research and Development, 6(9). https://doi.org/10.24940/ijird/2017/v6/i9/SEP17059

Dawson, C., Veliziotis, M., \& Hopkins, B. (2017). Temporary employment, job satisfaction and subjective well-being. Economic and industrial democracy, 38(1), 69-98. https://doi.org/10.1177/0143831X14559781

Dransfield, R. (2001). Corporate strategy. Heinemann.

Easterby-Smith, M., Thorpe, R., \& Lowe, A. (1991). Management Research: An Introduction. Sage Publications. London, UK.

Freeborn, D. K., \& Hooker, R. S. (1995). Satisfaction of physician assistants and other no physician providers in a managed care setting. Public Health Reports, 110(6), 714.

Gil, A. J., \& Mataveli, M. (2017). Learning processes and job satisfaction in the Spanish wine sector: The moderating effect of organizational size and employees' educational level. Personnel Review, 46(3), 624-643. https://doi.org/10.1108/PR-01-2015-0013

Hoppock, R. (1935). Job Satisfaction. Oxford, England: Harper.

Hui, C. H., Yee, C., \& Eastman, K. L. (1995). The relationship between individualism-collectivism and job satisfaction. Applied Psychology, 44(3), 276-282. https://doi.org/10.1111/j.1464-0597.1995.tb01080.x

Jooste, K. (Ed.). (2003). Leadership in health services management. Juta.

Judge, T. A., Heller, D., \& Mount, M. K. (2002). Five-factor model of personality and job satisfaction: A meta-analysis. Journal of applied psychology, 87(3), 530. https://doi.org/10.1037/0021-9010.87.3.530

Kreitner, R. K. A.(2004). Organizational Behavior. Chicago: Irwin. McGraw Hill. https://trove.nla.gov.au/version/49139202 
Kreitzer, M. J., Wright, D., Hamlin, C., Towey, S., Marko, M., \& Disch, J. (1997). Creating a healthy work environment in the midst of organizational change and transition. Journal of Nursing Administration, 27(6), 35-41. https://doi.org/10.1097/00005110-199706000-00011

Lewy, R. M. (1991). Employees at risk: protecting the health of the health care workerd Robert M. Lewy. Van Nostrand Reinhold.

Lu, H., While, A. E., \& Barriball, K. L. (2005). Job satisfaction among nurses: a literature review. International journal of nursing studies, 42(2), 211-227. https://doi.org/10.1016/j.ijnurstu.2004.09.003

Malhotra, N. K., Kim, S. S., \& Patil, A. (2006). Common method variance in IS research: A comparison of alternative approaches and a reanalysis of past research. Management science,52(12), 1865-1883. https://doi.org/10.1287/mnsc.1060.0597

Miller-Rosser, K., Chapman, Y., \& Francis, K. (2009). The use of oral testimony when reconstructing nursing history: a Saudi Arabian experience. Singapore Nursing Journal, 36(1), 23.

Mitchell, J. (2009). Job satisfaction and burnout among foreign-trained nurses in Saudi Arabia: A mixed-method study. $\mathrm{PhD}$ thesis, University of Phoenix, Phoenix, AZ. https://www.researchgate.net/publication/36711977

Moorhead, G., \& Griffin, R. W. (1998). Managing people and organizations: Organizational behavior. https://trove.nla.gov.au/work/7755342

Schoombie, J. C., van der Merwe, J. M., \& Kruger, L. M. (2014). The stress of caring: The manifestation of stress in the nurse-patient relationship. Social Work/Maatskaplike Werk,41(4), 388-408. https://doi.org/10.15270/41-4-318

Smits, S. J. (1972). Counselor job satisfaction and employment turnover in state rehabilitation agencies: A follow-up study. Journal of Counseling Psychology, 19(6), 512. https://doi.org/10.1037/h0033561

Sumner, M., \& Niederman, F. (2004). The impact of gender differences on job satisfaction, job turnover, and career experiences of information systems professionals. Journal of Computer Information Systems, 44(2), 29-39.

Swansburg, R. C. (1996). Management and leadership for nurse managers. Jones \& Bartlett Learning. https://trove.nla.gov.au/version/45627708

Wright, B. E. (2001). Public-sector work motivation: A review of the current literature and a revised conceptual model. Journal of public administration research and theory, 11(4), 559-586. https://doi.org/10.1093/oxfordjournals.jpart.a003515

Zaghloul, A. A., Al-Hussaini, M. F., \& Al-Bassam, N. K. (2008). Intention to stay and nurses' satisfaction dimensions. Journal of multidisciplinary healthcare, 1, 51. https://doi.org/10.2147/JMDH.S3804

Zeffane, R., \& Bani Melhem, S. J. (2017). Trust, job satisfaction, perceived organizational performance and turnover intention: A public-private sector comparison in the United Arab Emirates. Employee Relations, 39(7), 1148-1167. https://doi.org/10.1108/ER-06-2017-0135

Zikmund, W. G. (2003). Business research methods. Mason, OH : Thomson/South-Western.

\section{Copyrights}

Copyright for this article is retained by the author(s), with first publication rights granted to the journal.

This is an open-access article distributed under the terms and conditions of the Creative Commons Attribution license (http://creativecommons.org/licenses/by/4.0/). 